\title{
Research Paper: Experience of Primary Health Care Workers' Involvement in Response to Arasbaran Twin Earthquakes in 2012
}

\author{
Javad Babaie $^{1^{*}}$ (D), Masoumeh Golizadeh ${ }^{1}$ (D), Leila Doshmangir ${ }^{1}$ (D)
}

1. Department of Health Services Management, Iranian Center of Excellence in Health Management, School of Management and Medical Informatics, Tabriz Health Services Management Research Center, Tabriz University of Medical Sciences, Tabriz, Iran.

\begin{tabular}{|l|l|}
\hline $\begin{array}{c}\text { Use yourdevic to scan } \\
\text { and read thearticle online }\end{array}$ & $\begin{array}{l}\text { Crtation: Babaie J, Golizadeh M, Doshmangir L. Experience of Primary Health Care Workers' Involvement in Response to } \\
\text { Arasbaran Twin Earthquakes in 2012. Health in Emergencies and Disasters Quarterly. 2019; 5(2):79-90. http://dx.doi.org/10.32598/ } \\
\text { hdq.5.2.62.3 }\end{array}$ \\
doi http://dx.doi.org/10.32598/hdq.5.2.62.3
\end{tabular}

\section{(1) (8)}

Article info:

Received: 02 Aug 2019

Accepted: 08 Dec 2020

Available Online: 01 Jan 2020

\section{Keywords:}

Disaster, Primary healthcare workers, Health effects, Natural hazards, Response

\section{ABSTRACT}

Background: One of the most important concerns after disasters is managing their health consequences. This study examines the experiences of Primary Healthcare Workers (PHCWs) who involved in managing the health effects of the Arasbaran twin earthquakes of August 2012.

Materials and Methods: This study was conducted using a qualitative approach. Data were collected through semi-structured deep interviews. The collected data were analyzed by content analysis using the code extraction of subthemes and themes. Study participants included health managers, healthcare workers, and individuals who received the health services in response to the health effects of the Arasbaran twin earthquakes. A total number of 16 participants were interviewed. The study sample was selected purposefully.

Results: Interview analysis provided 14 subthemes and five main themes, including the lack of preparedness, the challenges of the PHCWs' contributions in providing healthcare, the inessentiality of the PHCWs' involvement in health response, the continuity of healthcare by the PHCWs, and the facilitation of coordination.

Conclusion: The involvement of the PHCWs in managing the health effects of the earthquakes was a successful experience that could prevent health problems. Challenges faced during this experience were mainly caused by the lack of preparedness.

\section{* Corresponding Author:}




\section{Introduction}

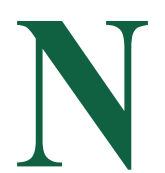

atural hazards are an integral component of our environment [1], however, their adverse impacts affect people's lives in vulnerable communities. These effects are sometimes so extensive that they are beyond the community capacity to respond and manage. In these situations that labeled as a disaster the assistance of other communities is often required [2].

According to the United Nations reports, more than 700000 people were killed, over 1.4 million were injured, and 23 million were displaced and became homeless because of disasters, during 10 years (2005-2015) [3]. In 2014, 324 disasters occurred worldwide. In these disasters, 7823 people were killed and 140.8 million were affected or victimized [4]. Also, experts emphasize that disasters have had an upward trend owing to climate changes in recent years; they suggest a continued increase in disaster occurrence for the future [5].

All specialists and references highlight the fact that Iran is prone to various hazards because of its geographic extent and location. Also, the historical data confirmed that Iran is unsafe in this regard [6]. From 1970 to 2010, 10105 natural hazards have occurred in Iran. During these 40 years, 115654 people died and 153483 were injured and disabled [7, 8]. In 2012, 217 floods led to financial losses and casualties [9]. Moreover, 1401 health facilities were destroyed or affected by disasters, 127 health care workers died, and more than 640 were injured, during 10 years (2001-2011), in Iran [10].

The most common outcomes of disasters include the destruction of livelihood and infrastructure, the disruption of society functions, the destruction of health centers [10], physical damages, mental effects, and mortality [11]. The response of the Health System (HS) is considered as one of the core, essential, and presumably the most important component of disaster responses. The timely and effective operation of HSs can play a decisive role in decreasing mortality and increasing disaster survival [12]. Evidence states that the preparedness of the HSs and their timely response can dramatically reduce the casualties of disasters [13].

Disaster response is accompanied by several challenges. Herein, not only the need for healthcare is greatly increased but also the health services are impaired [14]. In such cases, the HSs should try to increase their capacity to provide services using other sources [15]. The HSs have responded to disasters in several ways $[15,16]$, examples are provided in the following. During the Taiwan earthquake in 1999, multidisciplinary teams conducted a rapid assessment and designed a surveillance system in the first three days to monitor the spread of communicable diseases.

A temporary health and medical aid team was launched in the first week [17] to attend to the victims of Hurricane Floyd in North Carolina, where 20 health teams were already deployed [18]. On August 11, 2011, two fairly strong earthquakes struck the East Azerbaijan Province in the Northwest of Iran. These twin earthquakes (with the magnitudes of 6.2 and 6.3 on the Richter scale) destroyed Ahar, Harris, and Varzeqan districts; about 300 people lost their lives, 3309 were injured, and more than 85000 were affected.

The East Azerbaijan earthquake of 2012 struck a wide extent of areas that mostly included rural. During this disaster, the Minister of Health visited these areas and ordered to set up the Health Relief Posts (HRPs) in all villages with more than 20 households [19]. In the HS of Iran, primary healthcare is provided by the Ministry of Health through a well-designed system that includes the health houses in villages, rural health centers, and district health management systems. Thus, the health center of the East Azerbaijan province set up the HRPs, with the participation of the earthquake-affected counties and the Primary Healthcare Workers (PHCWs) of other provinces. These PHCWs provided health services for several months.

Several reports and evidence are available regarding the success of Iran's healthcare network [20], which is considered the pride of the country by international organizations. However, the authors did not find any evidence that investigates the efficacy of the health system in response to disasters and regards the potential ability of the primary healthcare network and its staff. Thus, considering the novelty of this event in the country, the unique and special nature of the provision of primary healthcare services in Iran, and the lack of documentation on this experience, the present study aimed to document this experience using a scientific method, and examine its strengths and weaknesses.

\section{Materials and Methods}

In this qualitative study, data were collected using indepth and semi-structured interviews. The average length of interviews was 76 minutes, and they were continued until data saturation. Study participants included decision-makers, responsible experts, and specialists from the expert groups of the province's health center, managers, and healthcare providers in the earthquake-affected ar- 
eas (Ahar, Harris, and Varzeqan). The study sample was purposefully selected and comprised the following: those who were interested in participating in interviews and had enough information, those who actively participated in the response phase, and those who received primary health care services provided by the PHCWs. Based on their previous knowledge and experiences, the researchers developed an interview guide. After obtaining consent from the Vice-Chancellor of Health of the Tabriz University of Medical Sciences, the researchers were referred to the interviewees and coordinated with them. The interviews continued until the data saturation was reached.

During the interviews, the interviewer initially presented a summary of the objectives of the study to the interviewee, then, The participants were interviewed. Based on the responses of the interviewees, more detailed questions were asked to extract their rich experiences. All responses were recorded and immediately extracted. After the transcription, the copy was returned to the participants for corrections (verbally).

The interview questions and the oral responses of the participants were originally in the local language (Turkish) and were translated to English by the researchers. No issue occurred for discussions during the participation of individuals with little or no literacy. During the interviews, the reflection and feedback method was used to ensure data consistency and accuracy, which were enhanced by examining the rich experiences of the participants. The interviews were focused on the following issues: Why were the PHCWs (Behvarzan) involved in responding to the consequent health effects of earthquakes? How was your experience? Also, residents (who were affected by earthquakes) were interviewed regarding the benefits they received using the facilities provided by the PHCWs.

The obtained data were simultaneously analyzed with content analysis. The codes were extracted from the interviews and collated as themes and subthemes. The extracted codes, subthemes, and themes were presented to some participants and relevant experts (health professionals in disaster and emergency medicine) through further interviews to examine and verify the reliability, validity, credibility, dependability, and conformability of the themes and subthemes [21-24].

The written informed consent was obtained from the participants and the authorities of the province's health center for the interviews. They were allowed to refuse to address any questions they did not wish to respond to, and withdraw participation at any stage of the study. Also, the par- ticipants were recommended not to mention their names and characteristics to maintain information confidentiality.

\section{Results}

A total number of 16 employees and health managers, including 13 males and 3 females, were interviewed. Out of 16 participants, three of them had a high school diploma, seven had a bachelor's degree, one had a master's degree, and five were general practitioners. Two practitioners had less than 14 years of job experience and three had more than 24 years of work experience. Three people were aged $14-19$ years and eight were aged $20-40$ years. From disaster-affected areas, 11 residents participated in the study.

The analysis of the interviews resulted in 424 codes. Some of the redundant codes were removed and others were merged, eventually, 160 codes resulted from all the primary codes. Similar codes were placed under the same themes, and resulted in 14 subthemes. Again, the obtained subthemes were placed under the same themes and five main themes were formed:

\section{The lack of preparedness}

2. The challenges of the PHCWs' contributions in providing healthcare

3. The inessentiality of the PHCWs' involvement in health response

\section{The continuity of healthcare by the PHCWs}

\section{The facilitation of coordination}

Table 1 presents the details of the codes, themes, and subthemes.

\section{Lack of preparedness}

The lack of preparedness was a topic that almost all contributors agreed on. The participants' statements indicated that neither the PHCWs (Behvarzan) nor the organizations (health centers in the East Azerbaijan province and health centers in the counties) were prepared. Thus, this theme was divided into two subthemes: the lack of individual preparedness and the lack of organizational preparedness.

\section{Lack of individual preparedness}

The participants repeatedly mentioned that the PHCWs were not prepared enough to serve in earthquake-affected areas and they might have been surprised. Besides, the PHCWs were unaware of where they would be deployed, 
what services they would provide, and at what conditions and by which facilities they would serve. The examples of the statements from the participants are presented below.

P1: "We had not been educated before; first aid was only in our courses". P2: "We were not ready beforehand for such a situation".

\section{Lack of organizational preparedness}

The provincial health center did not have any prior plan to manage the health effects of earthquakes. This lack of preparedness was fairly general and included the lack of instruction, guidance, equipment, supplies, and related training. Some of the contributors' statements were as follows:

P3: "No possibilities were foreseen. In the early days, we did not even have job descriptions nor did we have any form and instructions for the provision of services". P4: "Because nothing was forthcoming, we were asked to settle in the area and wait for other things".

Challenges of the $\mathrm{PHCWs}^{\prime}$ contribution in providing healthcare during emergencies

After the earthquakes, there were no plans regarding the involvement of the PHCWs. After the announcement of the Minister of Health, the Tabriz University of Medical Sciences was somewhat surprised and obliged to involve the PHCWs in a forced condition. Therefore, there was an initial resistance. Also, because of the unplanned conditions, there were many challenges, including the initiation and continuation of the activities, the difficulties of serving during emergencies, the lack of data on the health status of the area, the difficulties of working in emergencies, and the difficulties of working in a tent.

Challenges in initiating and continuing the services

Many participants stated that they voluntarily wanted to be deployed to the earthquake-affected areas, even before formal requests by the authorities. Practically, they faced many challenges both at the initiation of their service and before that. They did not have experience in disasters and were not aware of where they would be deployed or what equipment, supplies, and facilities were needed. Therefore, they were concerned about what they were doing. Furthermore, there was no definite place for providing care in rural areas. However, the tents were installed as the HRPs in the villages and the PHCWs settled inside them.

In several villages, the Behvarzan was forced to work, live, and sleep in tents. The tents lacked basic facilities, such as water, food and cooking essentials, toilets, bathrooms, refrigerators, and heaters. Because of the rural environment, reptiles and other wild animals could enter the tents, hence, the safety of the PHCWs was compromised. Despite these challenges, many of the PHCWs were interested in volunteering in the beginning. Nevertheless, the difficulty of serving during emergencies overpowered the initial feelings of altruism. Apart from family-related issues, financial issues, burnout, and fatigue due to serving in the tents were problems that gradually turned into the daily challenges for the PHCWs.

Lack of data on the health status of people in the earthquake-affected areas

Primary healthcare requires information on the health status of the population, however, no such information was available in the earthquake-affected areas. Most of them were on-the-move villages (villages that do not have any health facilities; the healthcare is provided only one day per month) that lacked basic information, also, the homes were destroyed and health records were not available. Besides, the composition of the village population had changed because of the migration of people from other areas. Therefore, the health status of the region remained unclear. The PHCWs were forced to undertake a population census and extract the required information.

Difficulties in providing services during emergencies

Earthquakes destroyed many rural buildings. Basic infrastructure facilities, such as water supply and distribution systems, wastewater collection and treatment, and communications, were severely damaged. The tents were usually located in a local area near the village houses, thus, the activities of excavating machines, malodor due to the improper disposal of feces and sewage, wind blowing, direct sunlight, falling, and the lack of light made it difficult to work in a tent.

Some of the participants' comments on this issue were as follows

P5: "I was interested in going from the first moment". P6: "We were early afraid of what we would do". P3: "In the beginning, everyone feels altruism, empathy, humanity, all of them, not financial matters... ". P6: "The Behvarzan and colleagues are tired". P3: "They are constantly calling and asking how long this will last". P5: "Nothing was inside the tent, but two blankets, a rug, gallons, and flasks". P7: "The tent had many problems. 
Table 1. Raised themes from the coding process

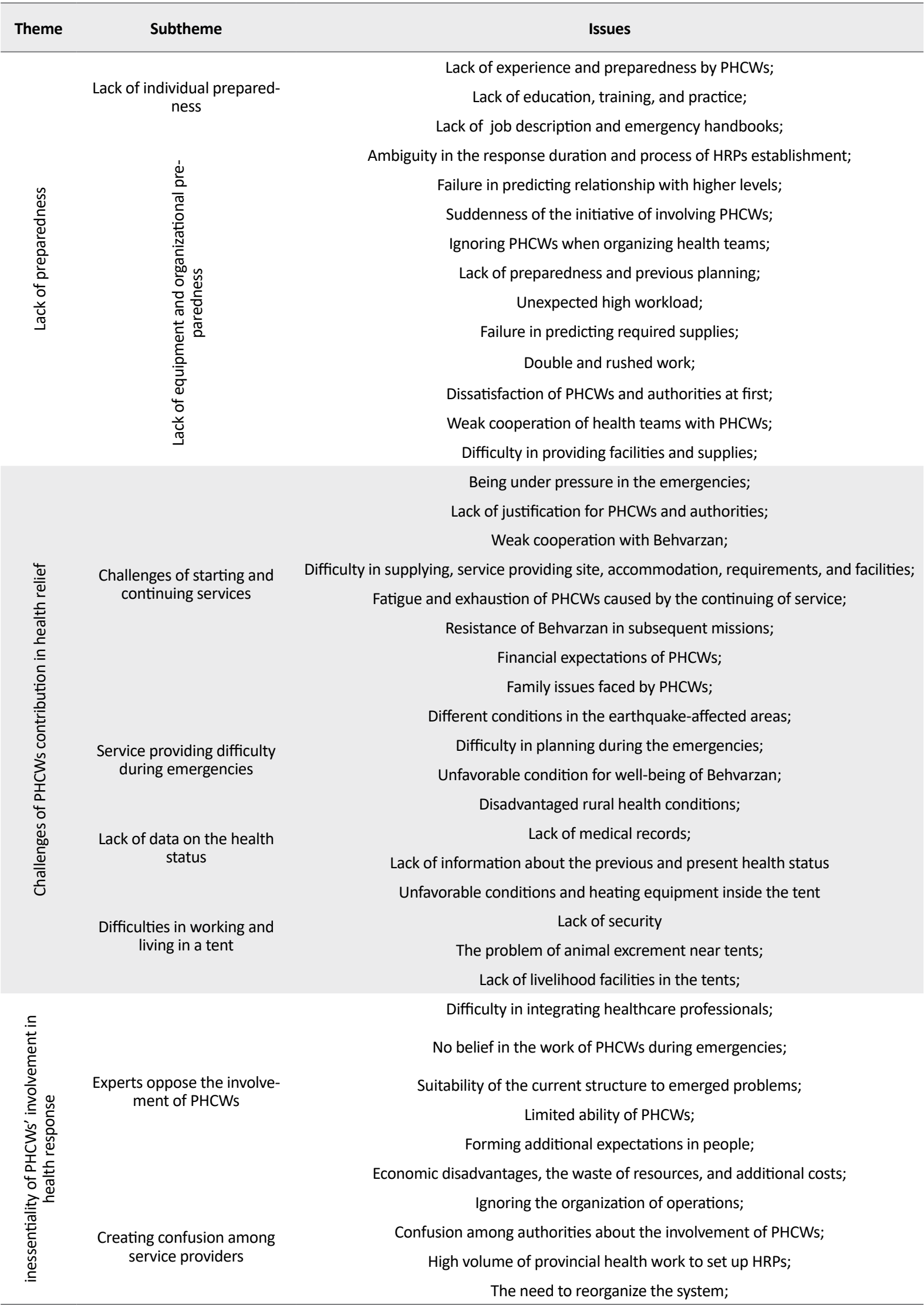




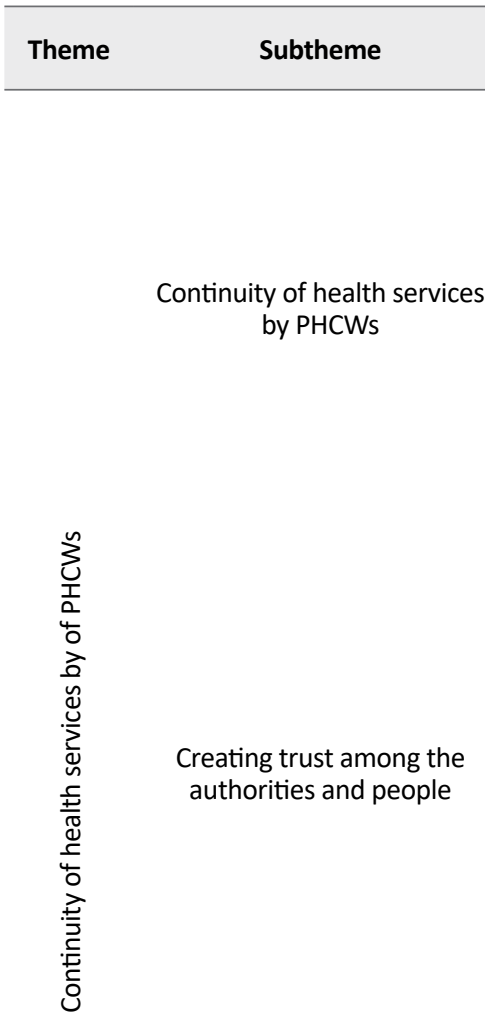

Special features of PHCWs

Filling in for the inactivity of local PHCWs and the lack of inter-sectorial coordination

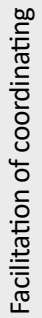

Establishing and continuing interagency coordination
Issues

Active service provision;

Patients follow-up;

Voluntary and motivational services;

Reducing the workload of the health teams;

Preventing interruption of health services;

Stabilizing the health condition;

Completion of the communication circle;

Being reliable for the officials and the people;

Relieving anxiety of the public and authorities;

Confidence of the authorities on the efficiency and effectiveness of PHCWs;

Facilitating accessibility and providing 24-hour services;

Build trust, confidence, and peace in people;

Creating a communication link;

Being a health watch and information source

Facilitating the delivery of services;

They are from the rural area and familiar with the characteristics of the rural environment;

Effectiveness of PHCWs in rural environments;

Multifunctionality of PHCWS;

Strong and self-made character of PHCWs;

Specialty in providing services in rural areas;

Acceptance among people and a quick and easy connection with rural people;

Intimacy of PHCWs with people

Exhaustion and the disability of local PHCWs;

Establishment and maintenance of active health relief posts;

Usage of health personnel from HRPs;

Native care providers' cooperation with PHCWs;

Public's trust in providing donations to PHCWs;

Delivering healthcare items to healthcare providers;

Helping to manage and preserve donations;

Creating a safe and secure place to collect donations;

Coordination between facilities in the village;

Attracting the Islamic councils of the villages;

Collaborating and interacting with local councils;

Creating a link between different departments and people;

Attracting popular contributions. 
A heavy wind came; dust came in the tent". P8: "The situation was inappropriate. It was in front of the sun". P7: "At night, the health workers could not stay in the tent".

Inessentiality of the PHCWs' involvement in providing health response

According to some participants, there is no need for the involvement of the PHCWs in providing primary healthcare. They argued that merging with the PHCWs ruptured the service delivery structure and created confusion among service providers.

\section{Experts opposed the involvement of the PHCWs}

Some participants believed that the national plan for providing health services in villages was perfect and the responsibility of all villages in terms of health service coverage was clear. Thus, there was no need to change this plan. They believed that the use of PHCWs, particularly in low-populated villages, and the deployment of two groups for a limited population increased the costs in many cases. Establishing the HRPs, extending the activities of healthcare providers, feeding them, organizing activities, and compensating for their services with additional payment resulted in an extensive financial burden. Also, the establishment of the HRPs in every small village would raise people's expectations, which were practically impossible to fulfill during the emergencies. Moreover, some participants believed that the ability of the PHCWs to provide health services is limited and they only perform basic measures and provide primary healthcare. However, the health conditions and medical needs of people are acute, during major emergencies.

\section{Creating confusion among service providers}

In a short time after the twin earthquakes, the health teams were recalled and deployed to the area. Their range of activities, how they would provide health services, how they would report, and how they would communicate were routinely identified. Thus, this change confused the teams. Moreover, instead of focusing on regional health management, the authorities were involved in supporting the provision of support services for the HRPs. Some of the statements from the contributors were as follows:

P8: "We were opposed to the presence of PHCWs, and in reality, it was not needed".

P9: "It was very difficult to introduce and integrate them into the system".
P10: "Sometimes I found out that using half this force, we can do even better than this number of tasks...".

P11: "PHCWs can do a few things, eventually, they could only measure blood pressure, it is over. They cannot prescribe medication".

P12: "There were many expectations among the people, and people were also expecting more services".

\section{Continuity of health services}

According to the participants, the initiative of involving the PHCWs made the provision of health services continued and persistent, in the region. Also, the $24 \times 7$ presence of the PHCWs resulted in the health authorities to not worry about the changing conditions of the region.

\section{Continuity of service provision by the PHCWs}

The presence of the PHCWs in health houses has been actively providing primary health services in rural areas. The active provision of services made it possible for people to receive services without problems. When visiting health teams, all people in need were invited to receive services. The provided health instructions were later followed up by the Behvarzan. This made it possible to complete the communication loop and provide healthcare in its true and complete form.

\section{Creating trust among the authorities and residents}

The $24 \times 7$ presence of the PHCWs in the villages served as a source of reassurance for officials. They were confident that all health issues, particularly acute health problems, would be resolved quickly and daily. They notified the authorities about any changes in the health of the people during the day. Also, the people were reassured that someone was aware of the health issues and the primary health facilities were provided near their homes. Moreover, given that the jobs of people in rural areas prevented them from being present during the working hours, they could even receive the services during non-administrative hours and at night.

\section{Specific features of the PHCWs}

According to the law established for the PHCWs, they were selected from the villagers and were to return to the village and provide the services, after two years of education. Therefore, they were fully acquainted with the characteristics of the rural life, culture, and traditional customs. They could easily get in touch with the villagers, particularly women, and the villagers could commu- 
nicate with them, explain the problems, and follow their guidelines. Some of the participants' comments on this topic were as follows:

P13: "I saw confidence and tranquility; all colleagues say that they were kind of peaceful people in the countryside and this crisis; we saw that people considered them to be supporters". P15: "The health workers themselves are rural people who grew up in the village and understand the problems well and people accept them". P16: "There was also a quick connection between them and people because they understood each other very well".

\section{Facilitation of coordination}

The Behvarzan helped by connecting with the members of the Islamic councils of the villages, service departments, and other authorities who worked in the villages. Also, the presence of the PHCWs and the establishment of the HRPs led many benefactors and supporters to approach the tents and provide their help with confidence.

\section{Filling in for inactivity among native PHCWs}

Launching the HRPs helped all the healthcare workers to be deployed there and serve the villagers using the available facilities. Several healthcare workers and the nursing homeowners of the earthquake-affected areas were unable to provide services for various reasons. However, the PHCWs took over their jobs and cooperated with them at the HRPs.

\section{Managing public donations}

Many people who donated gifts to the affected families found the HRPs the best place to visit. The donors donated their gift to the reliable present people, by referring to the HRPs, delivering their gifts, or using the HRPs' guidance. Also, the health-related items and donations were delivered to the PHCWs; the HRPs kept the medicines to use in the tents, and delivered the rest to the health authorities.

\section{Creation and continuity of intersectional coor- dination}

The presence of the PHCWs in the village, their relationship with the villagers, and their representatives helped to coordinate and use all the facilities and address the health issues, in the village. The Behvarzan was a good link between the people and the other departments.Some of the interviewees' comments on this issue were as follows:
P18: "There was a good link between the health teams, the local HS, and the people. Also, if there was a case in the village, Behvarzan immediately reported and requested assistance. They and the teams solved problems in the emergencies by visiting the village".

\section{Discussion}

This study qualitatively reviewed the experience of the involvement of the $\mathrm{PHCW}$ in providing healthcare for the earthquake-stricken rural areas of the East Azerbaijan province in the summer of 2012. The analysis of interviews led to the formation of five main themes (the lack of preparedness, challenges faced by the PHCWs in providing healthcare during emergencies, the need of using PHCWs for providing health services, the continuity of healthcare in the presence of the PHCWs, and facilitating inter and intra-sectional coordination) and 14 subthemes.

Disasters result in numerous health-related requirements and demolish many service-providing infrastructures, such as health facilities. Although the most important requirement of people in the first days of a disaster is health services, the provision of these services always includes several challenges. The HSs worldwide are aware of these challenges and trying to increase their capacities to continue providing the required services. During the East Azerbaijan earthquake of 2012, Iran's HS acted in such a way by forming medical health teams to provide healthcare. Later, the PHCWs were deployed to the stricken area to provide primary health care. This initiative was the first experience of using a primary healthcare system with a special structure [20, 23], in Iran. However, the PHCWs were also used for other disasters occurring in Iran $[2,25]$. Several experiences of using HS responses to disasters are documented and published worldwide.

On the first day after the Chi-Chi, Taiwan, earthquake of 1999, an executive committee was formed, and places were set up to provide first aid and vaccination for tetanus. Also, the provisional medical teams performed rapid assessment in the first 3 days, and a surveillance system was designed to monitor the state of communicable diseases. Besides, the temporary healthcare teams were formed in the first week; the teams covered more than $90 \%$ of the residents in the camps. Assistance teams were also launched [17], because many healthcare workers were either injured or extremely tired and sometimes inaccessible. Healthcare teams formed during the ChiChi, Taiwan, earthquake may be similar to the ones formed during the East Azerbaijan earthquake. 
To respond to the consequent health effects of Hurricane Floyd (North Carolina, 1999), the healthcare team was employed in the area to organize responses. Also, the affected areas were divided into seven health zones and a sanitary coordinator was selected for each area to coordinate and provide health services. During the storm, 20 professional health teams were deployed to the area [18]. The primary healthcare staff were not used to respond, however, the existing team structure was applied.

After the 2011 terrorist attack in Norway, the proactive approach was initiated to prevent failure to meet required assistance for providing sanitation services. Furthermore, all survivors received health services in the first five months after the incident. This study did not address the strengths and weaknesses of the proactive approach used, however, the results revealed that more resources were needed to meet the health-related requirements of the affected people [2].

The lack of preparedness of the HSs for emergency services, which is a theme of the present study, has also been acknowledged in most previous studies [1, 3, 25]. The PHCWs and the region's HS were not individually prepared. They had no instructions, guides, service lists, etc., and were very confused in the first few days.

After the 7.6 magnitude earthquake in the western Sumatra, Indonesia, Fuady et al. reported that there was more emphasis on establishing health centers with primary care providers, and many steps were initiated to keep these centers up to date [21].

Alhaji reported that the challenges associated with managing emergencies in Africa included political instability and economic mismanagement, the inability of the HS to increase capacity, the shortage of personnel and money (inadequate budget and poverty), the lack of coordination between the state and federal agencies, discharge logistics (public transportation services), the lack of public awareness and response, the lack of training, and poor interpersonal participation [24]. Khanke et al. reported problems, such as human factors, coordination issues, facility and management-related issues, and cultural problems, as barriers to health services. Challenges, such as the lack of expert manpower, the confusion of invited people, the depression and crisis of local nurses and doctors, the lack of cooperation between local and new personnel, the lack of expertise, confusion among personnel, and the lack of the prediction of healthcare personnel's requirements were factors that required to be dealt in the disaster-stricken areas [10].
All the aforementioned factors of unpreparedness observed in the previous studies were also observed in the present study. Unfortunately, the HSs do not learn from the previous incidents and disasters and repeat the same mistakes in the following incidents.

Because the involvement of the PHCWs in providing healthcare in the region was not anticipated in the early days, their deployment to provide services and equipments was initially challenging and pressurized the HSs. Besides, the health teams in the region were confused about working with the PHCWs. Owing to continuous activity, many employees were tired and weary. Although they were deployed in the region for long and were replaced every other day or every 3 days with newly formed teams, they were resistant to future assignments because of the severity of the region's conditions and the inappropriate conditions of the tent.

Nelson reported the data and health information whereby the HSs usually seek to quickly assess health needs $[10,26,27]$. Also, a rapid assessment was conducted in the earthquake-affected areas of the East Azerbaijan [28], however, the results were not available and usable until the healthcare workers were active.

Although the importance of providing health services in disaster-stricken areas has been emphasized, it is believed that the system's capacity should be increased to provide the services. Also, it is believed that the existing system needs no manipulation. Practically, the PHCWs' system is considered a waste of money because of the limited ability that is mainly caused by the deployment in low-income villages and the formation of two-member groups. Thus, the services and benefits generated by the PHCWs were considered insignificant, compared with the cost they imposed on the HSs; even during emergencies, the HSs must comply with the economic principles [29].

As the health teams served a large number of villages, they allocated a limited time to each village and only attended to immediate health-related requirements. After they left the villages, the services were discontinued; given the conditions in the earthquake-affected areas, the officials constantly worried about the health status of the people. However, the permanent presence of the PHCWs in the region resolved this issue. Because the PHCWs were constantly available, the people were reassured. The characteristics and attributes of the healthcare providers were also beneficial.

One of the most common problems in disaster-stricken areas is the lack of coordination between the different sec- 
tors of the HS. This problem has also been addressed in previous studies [1]. The presence of the PHCWs resolved many coordination problems. Further, by receiving the support and participation of the people and their representatives, the PHCWs were able to provide good health facilities to the people and ensure the good health of the people.

\section{Conclusion}

Although the involvement of the PHCWs for managing the consequent health effects of the East Azerbaijan twin earthquakes was a new experience for Iran, it had several benefits, particularly, for building confidence in the authorities and the people, regarding the control of health issues in the affected regions. However, this experience included many disadvantages and challenges. Providing healthcare after disasters is the most important factor; the preparations, such as manpower, instructions, manuals, equipments, and supplies must be made in advance. Thus, the authors recommend that the healthcare personnel should participate in training exercises and be regularly trained. Cost centers for health issues must be built, and cost-effectiveness discussions should be considered. The continuity of service and the psychological, social, and welfare problems of the healthcare personnel during their deployment in extreme conditions should also be considered.

\section{Ethical Considerations}

\section{Compliance with ethical guidelines}

All ethical principles are considered in this article.

\section{Funding}

This research did not receive any grant from funding agencies in the public, commercial, or non-profit sectors.

\section{Authors' contributions}

Study designing, writing - original draft: Masoumeh Golizadeh; Data analysis: Javad Babaie, Masoumeh Golizadeh; Software, data collection, validation, writing - review \& editing: Javad Babaie; Resources and Supervision: All authors.

\section{Conflict of interest}

The authors declared no conflict of interest.

\section{Acknowledgments}

The authors would like to thank to the Tabriz University of Medical Sciences relief team who were in Kermanshah and helped us conducting the research.

\section{References}

[1] Aliyu A. Management of disasters and complex emergencies in Africa: The challenges and constraints. Annals of African Medicine. 2015; 14(3):123-31.

[2] Ardalan A, Babaie J, Banaye Jedi M, Moradian MJ, Arzanloo M, Hajizadeh A. Response operations of health system to Chaldoran 2012 flood: A case study. Journal of Search \& Rescue. 2012; 4(1):54-60.

[3] Ardalan A, Babaie j, Shaterzadeh MA, Ronaghi M, Mehdizadeh $\mathrm{K}$, Hamidirad $\mathrm{H}$, Yousefi H. Response of public health system to 5 December 2012, South Khorasan earthquake: A case study. Journal of Relief and Rescue. 2014; 6(2):1-7.

[4] Ardalan A, Mowafi H, Khoshsabeghe HY. Impacts of natural hazards on primary health care facilities of Iran: A 10year retrospective survey. PLoS Currents Disasters. 2013; 5:ecurrents. [DOI:10.1371/currents.dis.ccdbd870f5d1697e4edee5eda12c5ae6] [PMID] [PMCID]

[5] Babaie J, Ardalan A, Vatandoost H, Goya MM, Akbarisari A. Performance assessment of communicable disease surveillance in disasters: A systematic review. PLOS Currents Disasters. 2015; 7:ecurrents. [DOI:10.1371/currents.dis. c72864d9c7ee99ff8fbe9ea707fe4465] [PMID] [PMCID]

[6] Lakbala P. Hospital workers disaster management and hospital nonstructural: A study in Bandar Abbas, Iran. Global Journal of Health Science. 2015; 8(4):221-6. [DOI:10.5539/gihs.v8n4p221] [PMID] [PMCID]

[7] United Nations. Sendai framework for disaster risk reduction: 2015-2030. United Nations, Sendai; 2015.

[8] Guha-Sapir D, Hoyois P, Below R. Ponserre S. Annual disaster statistical review 2014: The numbers and trends. WHO collaborating Centre for Research on the Epidemiology of Disasters (CRED), Institute of Health and Society (IRSS). Université catholique de Louvain - Brussels, Belgium; 2014. http://www.cred.be/sites/default/files/ADSR_2014.pdf

[9] Smith E, Wasiak J, Sen A, Archer F, Burkle FM Jr. Three decades of disasters research trend: A review of disaster-specific literature from 1977-2009. Prehospital and Disaster Medicine. 2009; 24(4):306-11. [DOI:10.1017/ S1049023X00007020] [PMID]

[10] Khankeh HR, Khorasani-Zavareh D, Johanson E, Mohammadi R, Ahmadi F, Mohammadi R. Disaster healthrelated challenges and requirements: A grounded theory study in Iran. Prehospital and Disaster Medicine. 2011; 26(3):151-8. [DOI:10.1017/S1049023X11006200] [PMID]

[11] Ardalan A, Kandi M, Osooli M, et al. Profile of natural hazards in I. R. Iran, Disaster and emergency health acad- 
emy, Iran's national institute of health research and SPH of Tehran university of medical sciences. 2012

[12] Babaie J, Shokri Soleimani Harag E, Sadeghi F. Epidemiology of urban flash floods in Iran, 3th national congress, on urban floods engineering. Tehran, Iran; 2015.

[13] Ardalan A, Mowafi H, Yousefi Khoshsabeghe H. Impacts of natural hazards on primary health care facilities of Iran: A 10-year retrospective survey. PLoS Currents Disasters. ecurrents. 2013 [DOI:10.1371/currents.dis.ccdbd870f5d1697e4edee5eda12c5ae6]

[14] Djalali AR, Casteren M, Hosseini Jenab V, Khatib M, Ohlen G, Kurland L. Hospital Incident Command System (HICS) performance in Iran: Decision making during disasters. Scandinavian Journal of Trauma. 2012; 20:14. [DOI:10.1186/1757-7241-20-14] [PMID] [PMCID]

[15] Djalali AR, Hosseinijenab V, Hasani A, Shirmardi K, Castrén $\mathrm{M}$, Ohlén $\mathrm{G}$, et al. A fundamental, national, medical disaster management plan: An education-based. Prehospital and Disaster Medicine. 2009; 24(6):565-9. [DOI:10.1017/ S1049023X00007524] [PMID]

[16] Khankeh HR. [Hospital preparedness in disasters: Iranian national plan (Persian)]. Tehran: University of Rehabilitation Sciences and Social Welfare; 2013.

[17] Saulnier DD, Brolin Ribacke K, Von Schreeb J. No calm after the storm: A systematic review of human health following flood and storm disasters. Prehospital and Disaster Medicine. 2017; 32(5):568-79. [DOI:10.1017/ S1049023X17006574] [PMID]

[18] Yamanouchi S, Sasaki H, Kondo H, Mase T, Otomo Y, Koido $Y$, et al. Survey of preventable disaster deaths at medical institutions in areas affected by the Great East Japan earthquake: Retrospective survey of medical institutions in Miyagi Prefecture. Prehospital and Disaster Medicine. 2017; 32(5):515-22. [DOI:10.1017/S1049023X17006501] [PMID]

[19] Cha MI, Choa M, Kim S, Cho J, Choi DH, Cho M, et al. Changes to the Korean disaster medical assistance system after numerous multi-casualty incidents in 2014 and 2015. Disaster Medicine and Public Health Preparedness. 2017; 11(5):526-30. [DOI:10.1017/dmp.2016; 202] [PMID]

[20] Wilson JA, McKenzie LK, McLeod WT, Darsey DA, Craig J. Improving disaster response efforts through the development of a disaster health care response system. Disaster Medicine and Public Health Preparedness. 2017; 11(5):600-4. [DOI:10.1017/dmp.2016.192] [PMID]

[21] Chen KT, Chen WJ, Malilya J, Twu SJ. The public health response to the Chi-Chi earthquake in Taiwan, 1999. Public health reports. 2003; 118(6):493-9. [DOI:10.1016/S00333549(04)50285-6]

[22] Davis MV, Mav Donald PDM, Cline JS, Baker EL. Evaluation of public health response to hurricanes finds North Carolina better prepared for public health emergencies. Public health reports. 2007; 122(1):17-26. [DOI:10.1177/003 335490712200103] [PMID] [PMCID]

[23] Mehrdad R. Health System in Iran. JMAJ. 2009; 52(1):69-73.

[24] Fuady A, Pakasi TA, Mansyur M. Primary health center disaster preparedness after the earthquake in Padong Pariumua, West Sumatra, Indonesia. BMC Research Notes. 2011; 4:81. [DOI:10.1186/1756-0500-4-81] [PMID] [PMCID]
[25] World Health Organization (WHO). Iranian health houses open the door to primary care. Bulletin of the World Health Organization. 2008; 86(8):585-6. [DOI:10.2471/ BLT.08.030808] [PMID] [PMCID]

[26] Stene A, Dyb G. Health service utilization after terrorism: A longitudinal study of survivors of the 2011 Utøya attack in Norway. Health Services Research. 2015; 15:158. [DOI:10.1186/s12913-015-0811-6] [PMID] [PMCID]

[27] TalatiS, Bhatia P, Kumar A, Gupta AK, Ojha CD. Strategic planning and designing of a hospital disaster manual in a tertiary care, teaching, research and referral institute in India. World Journal of Emergency Medicine. 2014; 5(1):35-41. [DOI:10.5847/wjem.j.is sn.1920-8642.2014.01.006] [PMID] [PMCID]

[28] Pouraghaei M, Jannati A, Moharamzadeh P, Ghaffarzad A, Hashemi Far M, Babaie J. Challenges of hospital response to the twin earthquakes of August 21, 2012, in East Azerbaijan, Iran. Disaster Medicine and Public Health Preparedness. 2017; 11(4):422-30. [DOI:10.1017/dmp.2016.153] [PMID]

[29] Khankeh HR, Mohammadi R, Ahmadi F. Barriers and facilitators of health care services in the time of natural disasters: A qualitative research. Quarterly Journal of Rehabilitation. 2005; 6(1):23-30. 
This Page Intentionally Left Blank 